\title{
Hemoglobin as a probe for estimation of nitric oxide emission from plant tissues
}

\author{
Neha Singh and Satish C. Bhatla* (1)
}

\begin{abstract}
Background: Plant roots contribute significant amount of nitric oxide (NO) in the rhizosphere as a component of NO in the ecosystem. Various pharmacological investigations on NO research in plants seek to quench endogenous NO by using externally applied NO quenchers, mainly 2-phenyl-4,4,5,5,-tetramethylimidazoline-1-oxyl 3-oxide (PTIO) and its more soluble form-carboxy-PTIO (CPTIO). Owing to serious limitations in its application CPTIO is no more a desired compound for such applications.

Result: Present work highlights the significance of using hemoglobin in the bathing solution to not only release endogenous NO from plant tissue but also to quench it in a concentration-dependent manner.

Conclusion: The protocol further demonstrates the diffusibility of $\mathrm{NO}$ from intracellular locations in presence of externally provided hemoglobin. The proposed method can have widespread applications as a substitute to debatable and currently used CPTIO as a NO scavenger.
\end{abstract}

Keywords: Hemoglobin, Nitric oxide, NO scavenger, Methemoglobin, MnIP-Cu

\section{Background}

Plants constitute an important source of biological NO emission in the terrestrial ecosystem $[1,2]$. Following the first observation of $\mathrm{NO}$ emission from herbicide-treated soybean leaves into the atmosphere [3], several studies have focused on NO emissions from detached plant tissues, cell suspensions and mitochondria [2, 4-7].

$\mathrm{NO}$ is a gaseous, lipophilic biomolecule which acts as a free radical with ability to diffuse across cell membranes, through the cytoplasm and migrate intracellularly as well as from cell to cell across the apoplast. It diffuses at a rate of $50 \mu \mathrm{m} \mathrm{s}^{-1}$. Its solubility is $1.9 \mathrm{mM}$ in aqueous solutions at $1 \mathrm{~atm}$ pressure. Half-life of NO in biological systems is reasonably short, less that $10 \mathrm{~s}$. The rapid movement and removal of cellular NO, makes it an ideal signaling molecule for cell to cell communication in plant tissues both in normal growth conditions and under stress [3, $8-12$ ]. It is a versatile molecule that can migrate and act concurrently in different cellular compartments and in

*Correspondence: bhatlasc@gmail.com

Laboratory of Plant Physiology and Biochemistry, Department of Botany, University of Delhi, Delhi 110007, India opposite directions. NO is biosynthesized in plants via multiple routes which are broadly classified as reductive and oxidative pathways. It is produced through both enzymatically in plastids, mitochondria, chloroplasts, and non-enzymatically in the apoplast [6, 13-19].

Pharmacological investigations on the modulation of plant growth and development by NO routinely employ PTIO and its more soluble form-cPTIO as a means to quench tissue NO. Of late, it has been reported that cPTIO usage as a NO scavenger exhibits duality in its action [20]. Depending on concentration, cPTIO can, at times, even contribute to further NO production, rather than serving as a $\mathrm{NO}$ quencher. cPTIO oxidizes $\mathrm{NO}$ by forming $\mathrm{NO}_{2}$ radical $\left(\mathrm{NO}+\mathrm{cPTIO} \rightarrow \mathrm{NO}_{2}+\mathrm{cPTI}\right)$, which in turn can react with $\mathrm{NO}$ to form $\mathrm{N}_{2} \mathrm{O}_{3}$ $\left(\mathrm{NO}_{2}+\mathrm{NO} \rightarrow \mathrm{N}_{2} \mathrm{O}_{3}\right)$. Thus, a reliable substitute $\mathrm{NO}$ quencher is required for various applications. Our recently published observations provided some evidence for the probable role of hemoglobin added in the growth medium on its ability to quench endogenous $\mathrm{NO}$ in sunflower seedlings [21, 22].

Ubiquitous occurrence of non-symbiotic hemoglobin $(\mathrm{Hb})$ suggests that it serves important functions in the 
regulation of plant metabolism [23-31]. Endogenous hemoglobin primarily transports oxygen to various regions. Hbs reversibly bind with oxygen and their rates of binding and dissociation differ depending on the type of $\mathrm{Hb}$. It also binds and scavenges $\mathrm{NO}$ and regulates its bioavailability in the tissues. In Arabidopsis thaliana, non-symbiotic class 1 and $2 \mathrm{Hbs}$ reduce nitrite to NO, and this reaction rate increase linearly with $\left[\mathrm{H}^{+}\right]$increasing [32]. NO thus produced exhibits a strong affinity for the ferrous heme, leading to the formation of ironnitrosyl-heme complex (Fe(II)-NO) as the final reaction product [33]. Hemoglobin scavenges NO through dioxygenation reaction where $\mathrm{NO}$ reacts with oxygenated hemoglobin $\left(\mathrm{OxyHb} ; \mathrm{HbO}_{2}\right)$ to produce methemoglobin (MetHb; in which heme iron is in ferric state) and nitrate. This reaction occurs at the rate of $6-8 \times 10^{7} \mathrm{M}^{-1} \mathrm{~s}^{-1}$ [34].

$$
\mathrm{HbFe}(\mathrm{II}) \mathrm{O}_{2}+\mathrm{NO} \rightarrow \mathrm{MetHb}+\mathrm{NO}_{3}^{-}
$$

Deoxygenated hemoglobin i.e. hemoglobin with ferrous heme iron, can also bind NO $[35,36]$. Under these conditions, NO is no longer available for physiological functions in the tissues.

$$
\mathrm{HbFe}(\mathrm{II})+\mathrm{NO} \underset{\text { Slow }}{\stackrel{\text { Fast }}{\rightleftarrows}} \mathrm{HbFe}(\mathrm{II}) \mathrm{NO}
$$

These observations form the basis of current investigations to demonstrate the application of hemoglobin in the bathing medium as an effective scavenger of NO released from live plant tissue. The evidence from the present work demonstrates the ability of hemoglobin to scavenge NO from all cellular and apoplastic components of the tissue system. The methodology thus proposed offers an alternative approach to scavenge endogenous $\mathrm{NO}$ in various pharmacological studies in plants.

\section{Materials and methods}

Plant growth conditions

Sunflower seeds (Helianthus annuus L., var. KBSH 54) were washed with a liquid detergent (teepol) under running tap water, disinfected using $0.005 \%$ mercuric chloride and again washed under running tap water for $1 \mathrm{~h}$. Seeds were then imbibed in distilled water for $2 \mathrm{~h}$ and placed on moist germination sheets irrigated with halfstrength Hoagland nutrient solution. Seedlings were grown up to 2 days in dark at $25^{\circ} \mathrm{C}$. Sunflower seedlings showing uniform growth pattern were selected for various analyses.

\section{Analysis of relative NO quenching ability of hemoglobin} Concentrated stock solution of hemoglobin (Sigmaaldrich, USA) was prepared fresh in distilled water for immediate use. To estimate the NO quenching ability of exogenously applied hemoglobin, $2 \mathrm{~d}$ old seedling roots were incubated for $30 \mathrm{~min}$ in dark in the absence or presence of variable concentrations of hemoglobin ranging from $250 \mu \mathrm{M}$ to $3 \mathrm{mM}$. Each tube contained three seedlings. NO released from seedling root in the bathing solution was analyzed using MnIP-Cu (a copper derivative of 4-methoxy-2-(1H-naphtho (2,3-d) imidazol-2-yl) phenol; MNIP-Cu [37]. Seedling roots dipped only in distilled water were served as control. Following incubation, the bathing solution from each tube was taken for estimation of NO released in solution by treating with $2.5 \mu \mathrm{M}$ of MnIP-Cu. NO released was monitored spectrofluorometrically (ex. $385 \mathrm{~nm}$, em. $492 \mathrm{~nm}$ ) and relative change in fluorescence was plotted to evaluate relative extent of $\mathrm{NO}$ released from tissue and quenched by variable concentrations of hemoglobin in solution.

\section{Estimation of methemoglobin formation}

Methemoglobin formation as a result of reaction between NO released from seedling roots and hemoglobin present in the solution was monitored spectrophotometrically at $406 \mathrm{nM}$. Oxygenated hemoglobin absorbs at a wavelength of $415 \mathrm{nM}$ and its reaction with NO lead to the formation of methemoglobin which shifts the absorbance of the product (metHb) to $406 \mathrm{nM}$.

\section{Visualization of NO in seedling roots in the absence or presence of hemoglobin}

To further validate the scavenging ability of exogenously provided hemoglobin, seedling roots were dipped in distilled water containing variable concentrations of hemoglobin $(2-3 \mathrm{mM})$ for $30 \mathrm{~min}$ in dark. Seedling roots dipped in distilled water served as control. After incubation, seedling roots were then incubated in $50 \mu \mathrm{M}$ of MnIP-Cu for $45 \mathrm{~min}$ (ex. $385 \mathrm{~nm}$, em. $492 \mathrm{~nm}$ ). Using confocal laser scanning microscopy (CLSM; Leica, Germany), root tips were visualized for NO localization both in the absence or presence of hemoglobin.

\section{Detection of nuclei in seedling roots using CLSM}

Seedling roots were incubated with 4,6-diamidino-2-phenylindole (DAPI; $2 \mu \mathrm{g} \mathrm{ml}^{-1}$ in distilled water) for $2 \mathrm{~min}$ to localize nuclei using CLSM (ex. $360 \mathrm{~nm}$ and em. $460 \mathrm{~nm}$ ).

\section{Co-localization of NO and mitochondria in the seedling roots}

Seedling roots were incubated in $50 \mu \mathrm{M}$ of MnIP$\mathrm{Cu}$ solution for $45 \mathrm{~min}$ and then dipped in $300 \mathrm{nM}$ of MitoTracker (Molecular Probes, USA) for $45 \mathrm{~min}$. NO and mitochondria signals were co-localized in the roottip tissues by CLSM at ex. $385 \mathrm{~nm}$; em. $492 \mathrm{~nm}$ for NO 
and at ex. $554 \mathrm{~nm}$; em. $576 \mathrm{~nm}$ for mitochondria. Colocalization rate and mean intensity of co-localization of $\mathrm{NO}$ and mitochondrial signal were calculated using software LAS-AF, version 2.7-9723.3.

\section{Statistical analysis}

All experiments were performed at least thrice and statistically analyzed by SPSS 22.0 statistical program (SPSS Inc, Chicago, IL, U.S.A.) using One-Way ANOVA.

\section{Results}

A novel fluorescence probe (a copper derivative of 4-methoxy-2-(1H-naphtho (2,3-d) imidazol-2-yl) phenol; MNIP-Cu; Fig. 1a) developed in the author's laboratory in recent past for spectrofluorometric quantification and visualization of NO in live cells [37], has been used in the present work to examine the NO quenching ability of hemoglobin provided in the bathing medium. NO released from $2 \mathrm{~d}$ old, dark-grown sunflower seedling roots were monitored in the absence or presence of variable concentrations of hemoglobin $(250 \mu \mathrm{M}-3 \mathrm{mM})$ in the bathing solution. Since hemoglobin in solution binds with NO released from roots, resulting in methemoglobin $\left(\mathrm{Hb}-\mathrm{Fe}^{\mathrm{III}}\right)$ formation and conversion of $\mathrm{NO}$ to $\mathrm{NO}^{3-}$, a $\mathrm{Hb}$ concentration-dependent decrease in the availability of free NO in solution is evident (Fig. 1b, c). Three millimoles of $\mathrm{Hb}$ leads to quenching of as much as $40 \%$ of NO released from roots as compared to control, thereby demonstrating the ability of externally available $\mathrm{Hb}$ to serve as a quencher of NO released from the tissue.

Exogenous $\mathrm{Hb}\left(\lambda_{\max } 415 \mathrm{nM}\right)$ per se does not cross cell membranes (being a high molecular mass molecule of $64.5 \mathrm{kDa}$ ) but it can easily bind diffusible endogenous NO in a concentration $(250 \mu \mathrm{M}$ to $3 \mathrm{mM})$-dependent manner and make it inaccessible as a free molecule in the bathing medium (forming methemoglobin; $\lambda_{\max } 406 \mathrm{nM}$ ) (Fig. 1d, e). This observation on $\mathrm{Hb}$ as a $\mathrm{NO}$ quencher carries significance for pharmacological investigations in plant cells where, so far, cPTIO have been extensively used as NO quenchers. Figures 2 and 3 provide detailed evidence for quenching of endogenous NO from sunflower seedlings root cells in response to externally provide $\mathrm{Hb}$ (2-3 mM). In addition to cytoplasm and apoplast, NO has also been localized in nuclei and mitochondria. The ability of exogenous $\mathrm{Hb}$ to trigger migration of $\mathrm{NO}$ from all these intracellular locations thus proves its (Hbs) scavenging ability (for NO) from all intracellular locations of the plant cells/tissues exposed to various pharmacological investigations.

\section{Discussion}

Hemoglobin is one of the hemoproteins, and NO is considered as a major regulatory component of the function of hemoproteins. NO can either activate or inhibit the activities of various hemoproteins by binding at the metallic center of heme. Furthermore, it is the oxidation state and the coordination environment of the iron center in the hemoproteins which determines the kinetics of NO binding with them [38]. Hexacoordination of heme molecule in non-symbiotic hemoglobin in plants enables it to bind with $\mathrm{NO}$ and scavenge it during hypoxic stress conditions [26]. Non-symbiotic hemoglobins possess ligand-binding characteristics different from that of symbiotic hemoglobins. Non-symbiotic Hbs exhibit high rate of oxygen binding than its rate of dissociation compared to symbiotic $\mathrm{Hb}$, which possess high rate of oxygen binding as well as its dissociation. This difference in ligand-binding efficiency of the two proteins is due to differences in heme-coordination state. Thus, in non-symbiotic $\mathrm{Hb}$, heme molecule is hexacoordianted compared to symbiotic $\mathrm{Hb}$ where it is pentacoordinated. Hemoglobin binds with both $\mathrm{NO}$ and $\mathrm{O}_{2}$ depending on the coordination state of heme molecule and performs the functions of either transportation of $\mathrm{O}_{2}$ or turnover/scavenging of NO. Symbiotic and erythrocyte hemoglobin is pentacoordinated which allows reversible binding of $\mathrm{O}_{2}$. Thus, they are capable of $\mathrm{O}_{2}$ transport and storage. However, non-symbiotic Hbs are hexacoordinated and exhibit very high avidity for $\mathrm{O}_{2}$. It exist as oxyhemoglobin under most physiological conditions and can efficiently scavenge NO via NO-dioxygenase activity [39-43]. Non-symbiotic hemoglobin expression is affected by a variety of stress conditions, such as hypoxia, cold stress and levels of cellular ATP $[26,27,31]$. In Arabidopsis, non-symbiotic $\mathrm{Hb}$ (AHb1) exhibits NOD activity in the presence of oxygen (Fig. 4). It removes NO using NADPH as electron donor leading to generation of nitrate and ferric hemoglobin, known as methemoglobin (metHb) [44]. High expression of nsHb in plants exhibits lot of significance as it enables plants to regulate high levels of NO, formed as a result of stress conditions, either by converting NO to nitrate via dioxygenation reaction or by forming nitrosylhemoglobin. Furthermore, it has been suggested that plant lines expressing high levels hemoglobin can prove to be better adapted to both normal and stress conditions [43].

Oxygenated hemoglobin $\left(\mathrm{HbO}_{2}\right)$ is considered as a good choice, and can effectively scavenge NO within concentration range from 125 to $500 \mu \mathrm{M}$ from both sunflower seedling roots and cotyledons tissue homogenates 


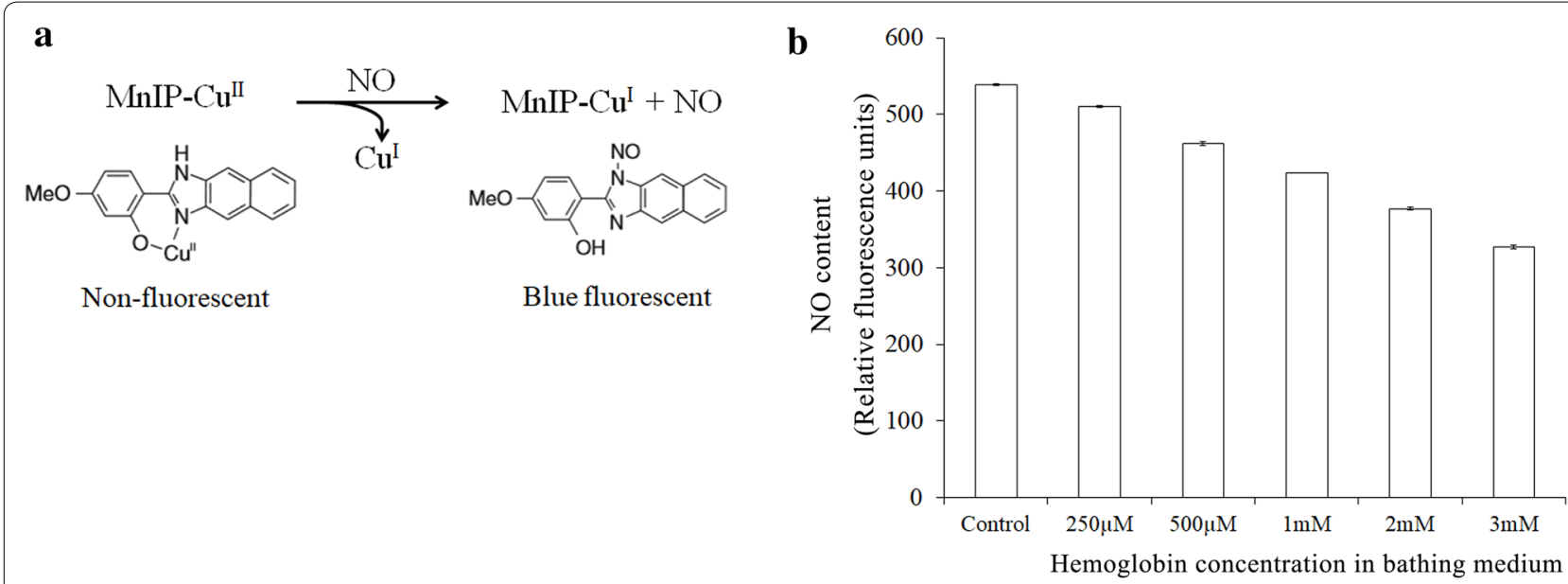

\section{c Hemoglobin-Fe $\mathrm{Fe}^{\mathrm{II}}-\mathrm{O}_{2}+\mathrm{NO} \longrightarrow$ Hemoglobin-Fe $\mathrm{III}+\mathrm{NO}^{3-}$ \\ Oxyhemoglobin $\left(\mathrm{HbO}_{2}\right)$ \\ Absorbs at $415 \mathrm{~nm}$}

\section{d}

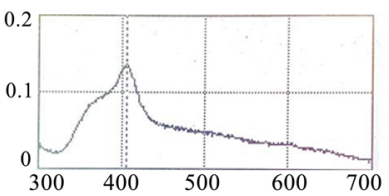

$250 \mu \mathrm{M} \mathrm{Hb}$

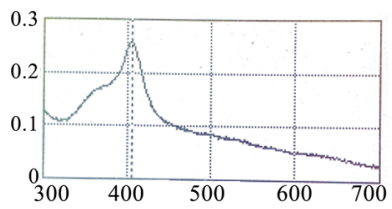

$500 \mu \mathrm{M} \mathrm{Hb}$

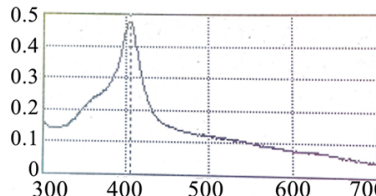

$1 \mathrm{mM} \mathrm{Hb}$

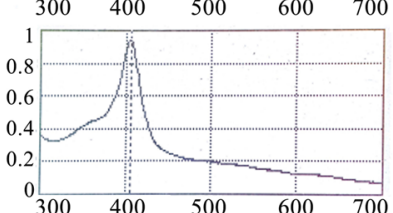

$2 \mathrm{mM} \mathrm{Hb}$

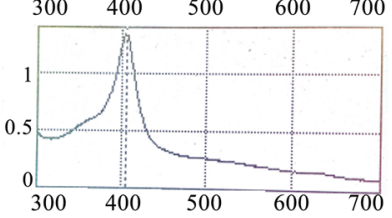

Fig. 1 a Mechanism of action of MnIP-Cu, a novel probe for detection of $\mathrm{NO}$ in plant systems. b Quenching of NO released from seedling roots by exogenous hemoglobin $(\mathrm{Hb})$ in a concentration $(\mathrm{Hb})$-dependent manner. NO released in solution from seedling roots bathed in varied concentrations of $\mathrm{Hb}$ was estimated using NO specific probe MnIP-Cu ex. $330 \mathrm{~nm}$, em. $460 \mathrm{~nm}$. c Conversion of oxyhemoglobin $\left(\mathrm{HbO}_{2}\right)$ to methemoglobin in the presence of NO. $\mathbf{d}$ Absorbance peak for formation of methemoglobin in the presence of NO released from seedling roots in the solution bathed in varying concentrations of hemoglobin ( $250 \mu \mathrm{M}$ to $3 \mathrm{mM}$ ) separately. e Increase in methemoglobin formation as a consequence of $\mathrm{NO}$ release from seedling roots in the bathing solution containing variable concentrations of hemoglobin ( $\mathrm{Hb})$. Note: Lower dosage of $\mathrm{Hb}$ in solution is insufficient in quenching $\mathrm{NO}$ from seedling roots 
a

\section{Control \\ (without $\mathrm{Hb}$ )}
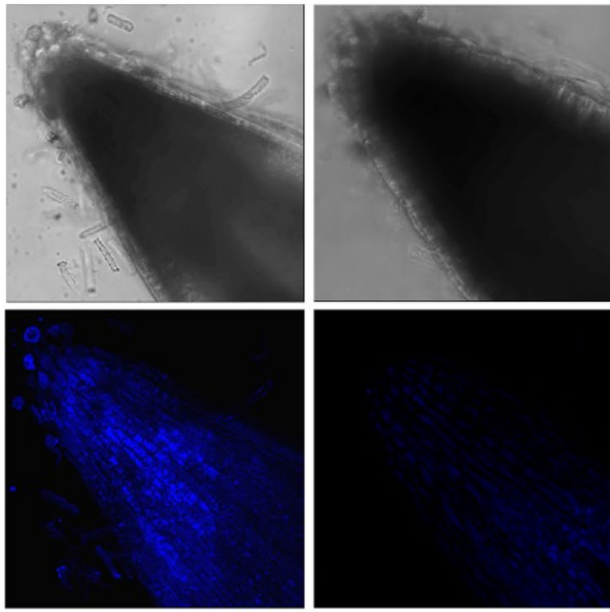

b

NO distribution in root cells

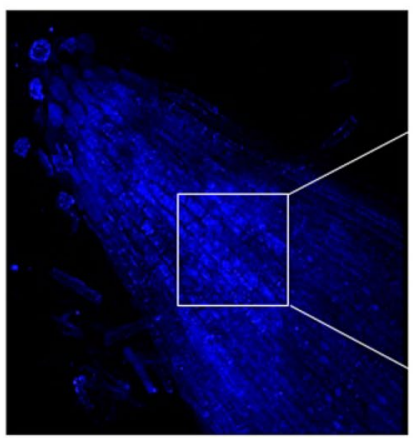

$2 \mathrm{mM} \mathrm{Hb}$
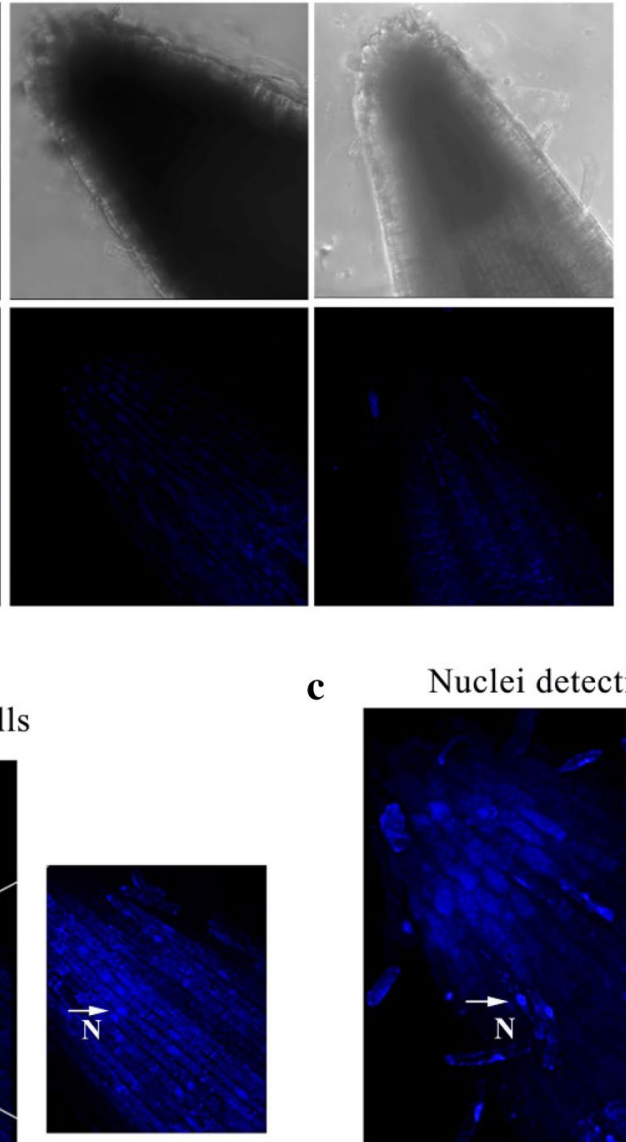

$3 \mathrm{mM} \mathrm{Hb}$

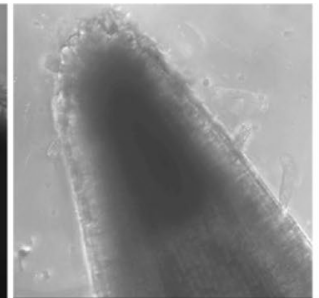

c
Visible image

Image after incubation with NO probe $\mathrm{MnIP}-\mathrm{Cu}$ Nuclei detection (DAPI)

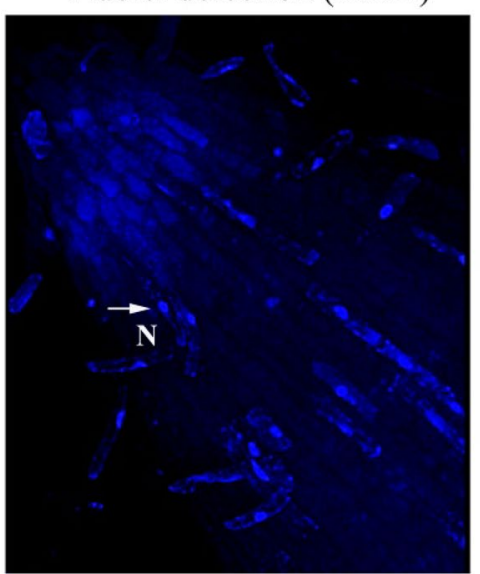

Fig. 2 a Extracellular hemoglobin $(\mathrm{Hb})$ as a quencher of endogenous $\mathrm{NO}$ from sunflower seedling roots. Seedling roots incubated in hemoglobin solution ( $2 \mathrm{mM}$ and $3 \mathrm{mM}$ ) for $1 \mathrm{~h}$ followed by incubation in NO specific probe MnIP-Cu for $1 \mathrm{~h}$. CLSM visualization of NO signal showed Hb concentration-dependent quenching of tissue NO. Roots were obtained from 2 day old dark-grown sunflower seedlings. Incubation medium without hemoglobin acts as control. b NO localization using CLSM in nuclei of root cells. Roots were obtained from 2 day old dark-grown sunflower seedlings. NO signal was visualized using MnIP-Cu. c Nuclei were visualized using DAPI. N Nuclei

[21]. The reaction between $\mathrm{NO}$ and $\mathrm{HbO}_{2}$ is rapid, stoichiometric and leads to formation of methemoglobin and nitrate $\left(\mathrm{NO}^{3-}\right)$ [45]. Due to its size $(64.5 \mathrm{kDa}), \mathrm{HbO}_{2}$ does not cross cell membranes but can facilitate free diffusion of endogenous $\mathrm{NO}$ and its subsequent scavenging in the bathing medium (present work). Furthermore, $\mathrm{HbO}_{2}$ works well with the externally applied NO donor which generate $\mathrm{NO}$ even in the extracellular compartments, 


\section{NO signal (MnIP-Cu) Mitochondroa (MitoTracker) Co-localized image}
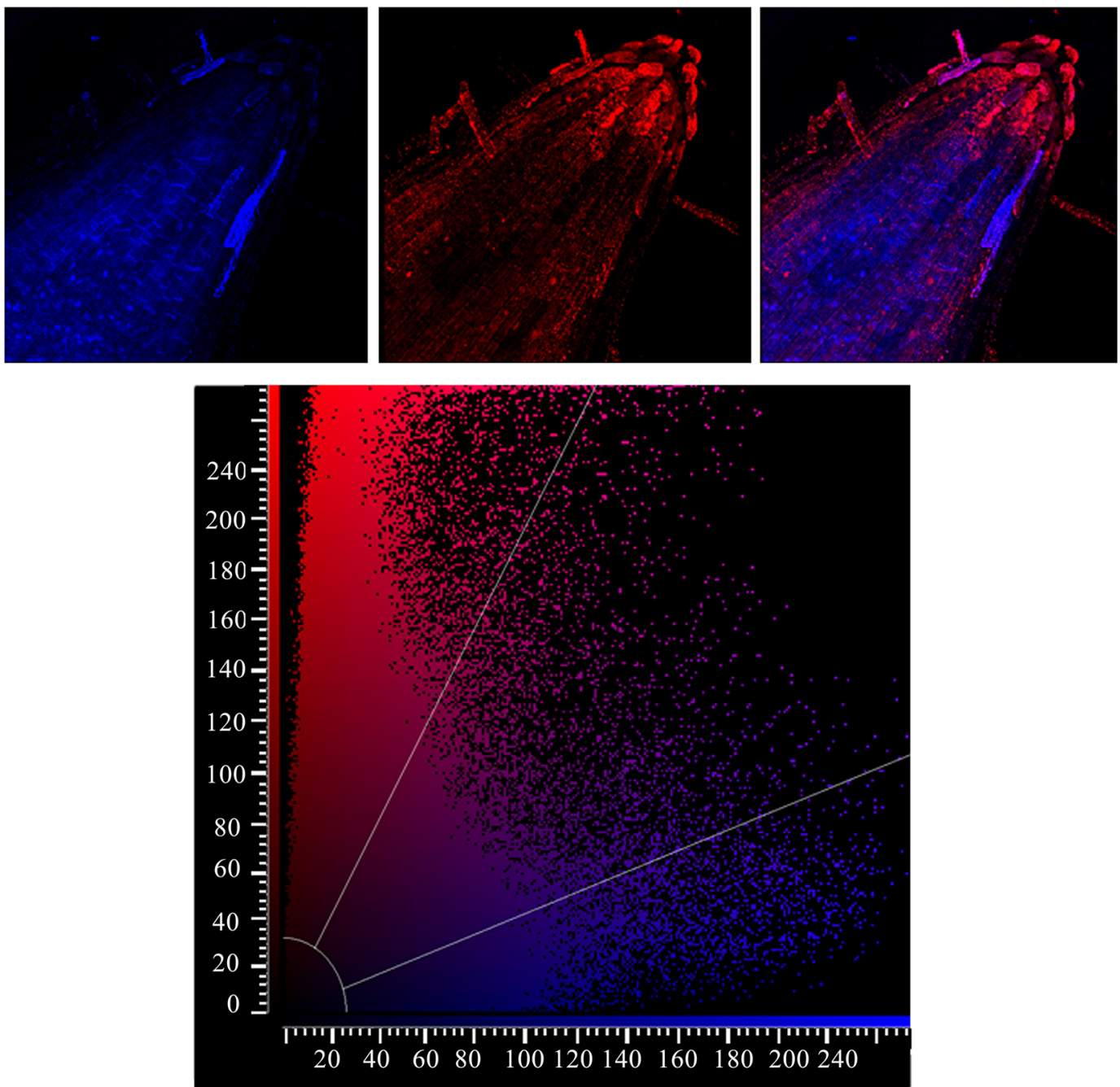

\section{Co-localization graph}

Fig. 3 Co-localization of $\mathrm{NO}$ and mitochondria in 2 day old, dark-grown sunflower seedling roots. Data analysis was done using software LAS-AF, version 2.7-9723.3. Co-localization rate-51.44\%. Mean intensity of co-localization of NO signal-41.41. Mean intensity of co-localization of Mitochondrial signal-37.39

such as NONOates than those which needs intracellular bioactivation to release NO, like organic nitrates. Also, $\mathrm{HbO}_{2}$ does not inhibit transnitrosation reactions.

\section{Conclusion}

In view of the above-stated features of hemoglobin and current observations, it is a more reliable alternative to cPTIO as a $\mathrm{NO}$ scavenger of tissue $\mathrm{NO}$ in pharmacological investigations in plant systems. It $(\mathrm{Hb})$ works efficiently in a concentration-dependent manner in efficiently quenching $\mathrm{NO}$ from plant tissues unlike cPTIO, which behaves differently (as NO quencher or as a source of NO) depending on its concentration in the medium. Thus, hemoglobin can be used as an efficient probe for estimation of NO emission from living tissues. 


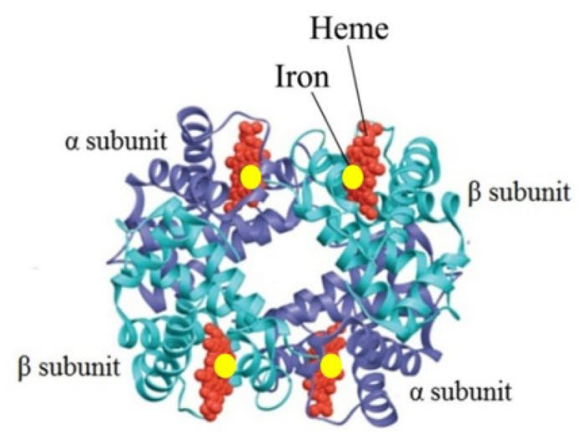

Tetramer of hemoglobin
Non-symbiotic $\mathbf{H b}^{\mathrm{Fe}(\mathrm{II})}$

(Anoxic conditions)

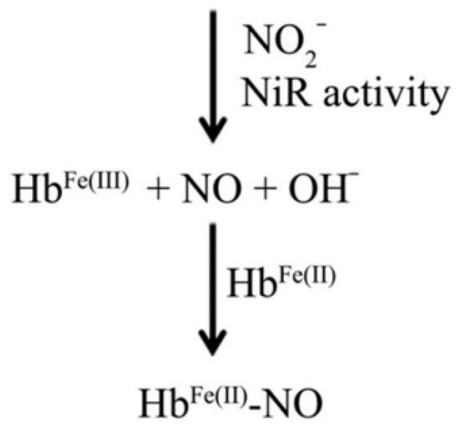

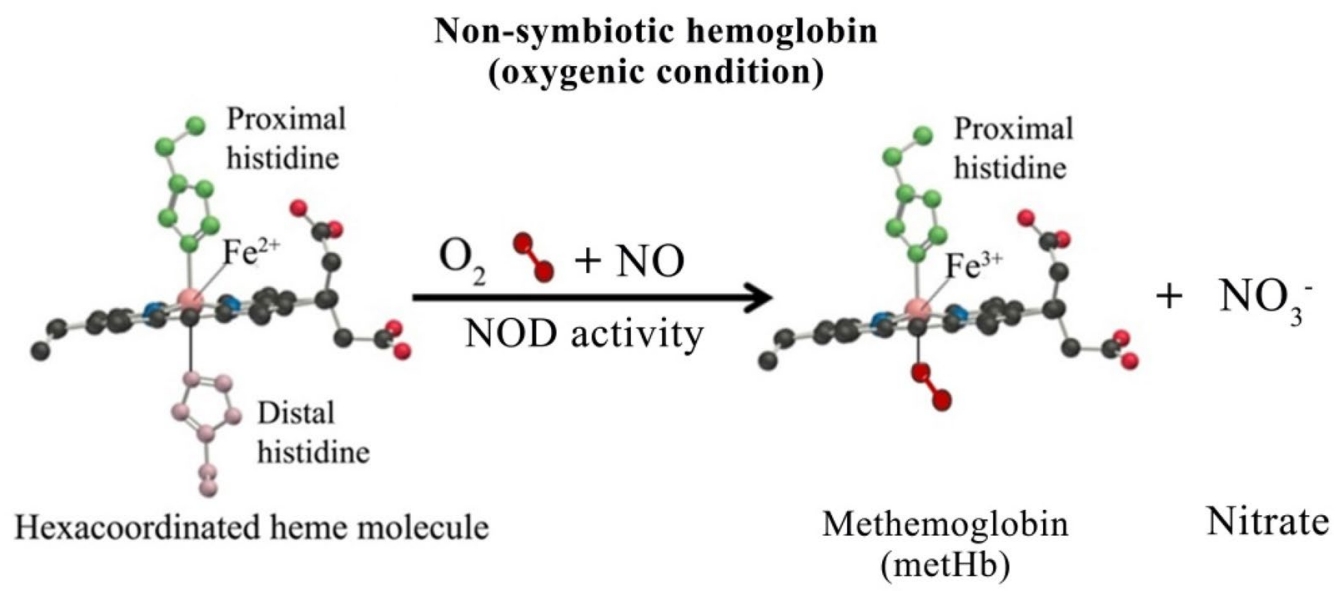

Fig. 4 Mechanism of non-symbiotic hemoglobin association with oxygen and NO in anoxic and oxygenic conditions. NOD NO-dioxygenase

\section{Abbreviations}

NO: nitric oxide; PTIO: 2-phenyl-4,4,5,5,-tetramethylimidazoline-1-oxyl 3-oxide; c-PTIO: carboxy-PTIO; MnIP-Cu: copper derivative of 4-methoxy-2-(1H-naphthol (2,3-d) imidazol-2-yl) phenol; ns Hb: non-symbiotic hemoglobin; metHb: methemoglobin.

\section{Authors' contributions}

Planning: Both the authors; Experimental work: NS; Writing of manuscript: both the authors. Both authors read and approved the final manuscript.

\section{Acknowledgements}

The authors are grateful to Joint UGC-Israel Science Foundation Research Project [F. No. 6-9/2017(IC)] for providing research funds.

\section{Competing interests}

The authors declare that they have no competing interests.

\section{Consent for publication}

Not applicable.

Ethics approval and consent to participate Not applicable.

\section{Publisher's Note}

Springer Nature remains neutral with regard to jurisdictional claims in published maps and institutional affiliations.

Received: 21 January 2019 Accepted: 15 April 2019

Published online: 23 April 2019

\section{References}

1. Wildt J, Kley D, Rockel A, Rockel P, Segschneider HJ. Emission of NO from several higher plant species. J Geophys Res Atmos. 1997;102:5919-27.

2. Chen J, Wu FH, Liu TW, Liu TW, Chen L, Xiao Q, Dong XJ, He JX, Pei ZM, Zheng HL. Emissions of nitric oxide from 79 plant species in response to simulated nitrogen deposition. Environ Pollut. 2012;160:192-200.

3. Klepper LA. Nitric oxide (NO) and nitrogen dioxide $\left(\mathrm{NO}_{2}\right)$ emissions from herbicide-treated soybean plants. Atmos Environ. 1979;13:537-42.

4. Lea US, Ten Hoopen F, Provan F, Kaiser WM, Meyer C, Lillo C. Mutation of the regulatory phosphorylation site of tobacco nitrate reductase results in high nitrite excretion an $\mathrm{NO}$ emission from leaf and root tissue. Planta. 2004;219:59-65.

5. Planchet E, Jagadis Gupta K, Sonoda M, Kaiser WM. Nitric oxide emission from tobacco leaves and cell suspensions: rate limiting factors and evidence for the involvement of mitochondrial electron transport. Plant J. 2005;41:732-43. 
6. Gupta KJ, Stoimenova M, Kaiser WM. In higher plants, only root mitochondria, but not leaf mitochondria reduce nitrite to $\mathrm{NO}$, in vitro and in situ. J Exp Bot. 2005:56:2601-9.

7. Chen J, Xiao Q, Wu FH, Pei ZM, Wang J, Wu YG, Zheng HL. Nitric oxide emission from barley seedlings and detached leaves and roots treated with nitrate and nitrite. Plant Soil Environ. 2010;56:201-8.

8. Pfeiffer S, Mayer B, Hemmens B. Nitric oxide: chemical puzzles posed by a biological messenger. Angew Chem Int Ed Engl. 1999;38:1714-31.

9. Neill SJ, Desikan R, Clarke A, Hancock JT. Nitric oxide signaling in plants. New Phytol. 2003;159:11-35.

10. Lamattina L, Garcia-Mata C, Graziano M, Pagnussat G. Nitric oxide: the versatility of an extensive signal molecule. Annu Rev Plant Biol. 2003;54:109-36

11. Shapiro AD. Nitric oxide signaling in plants. Vitam Horm. 2005;72:339-98.

12. Corpas FJ, Barroso JB, Carreras A, Valderrama R, Palma JM, del Río LA. Nitrosative stress in plants: a new approach to understand the role of NO in abiotic stress. In: Lamattina L, Polacco JC, editors. Nitric oxide in plant growth, development and stress physiology. Plant cell monographs, vol. 5. Berlin: Springer; 2006

13. Guo FQ, Okamoto M, Crawford NM. Identification of a plant nitric oxide synthase gene involved in hormonal signaling. Science. 2003;302:100-4.

14. Bethke PC, Badger MR, Jones RL. Apoplastic synthesis of nitric oxide by plant tissues. Plant Cell. 2004;16:332-41.

15. Corpas FJ, Barroso JB, del Río LA. Enzymatic sources of nitric oxide in plant cells: beyond one protein-one function. The New Phytologist. 2004;162:246-8.

16. Guo FQ, Crawford NM. Arabidopsis nitric oxide synthase 1 is targeted to mitochondria and protects against oxidative damage and dark-induced senescence. Plant Cell. 2005;17:3436-50.

17. Gupta KJ, Kaiser WM. Production and scavenging of nitric oxide by Barley root mitochondria. Plant Cell Physiol. 2010:51:576-84

18. Gupta KJ, Fernie AR, Kaiser WM, van Dongen JT. On the origins of nitric oxide. Trends Plant Sci. 2011;16:160-8.

19. Recalde L, Vázquez A, Groppa MD, Benavides MP. Reactive oxygen species and nitric oxide are involved in polyamine-induced growth inhibition in wheat plants. Protoplasma. 2018;255:1295

20. Arita NO, Cohen MF, Tokuda G, Yamasaki H. Fluorometric detection of nitric oxide with diaminofluoresceins (DAFs): applications and limitations for plant NO research. Plant Cell Monogr. 2006;5:269-80.

21. Singh N, Bhatla SC. Signaling through reactive oxygen and nitrogen species is differentially modulated in sunflower seedling root and cotyledon in response to various nitric oxide donors and scavengers. Plant Signal Behav. 2017;12:e1365214.

22. Singh N, Bhatla SC. Nitric oxide regulates lateral root formation through modulation of ACC oxidase activity in sunflower seedlings under salt stress. Plant Signal Behav. 2018;13:1-7.

23. Hebelstrup KH, Hunt P, Dennis E, Jensen SB, Jensen EØ. Hemoglobin is essential for normal growth of Arabidopsis organs. Physiol Plant. 2006;127:157-66

24. Bhattacharya S, Sen A, Thakur S, Tisa LS. Characterization of haemoglobin from Actinorhizal plants_an in silico approach. J Biosci. 2013:38:777-87.

25. Dordas C, Rivoal J, Hill RD. Plant haemoglobins, nitric oxide and hypoxic stress. Ann Bot. 2003:91:173-8.

26. Dordas C, Hasinoff BB, Igamberdiev AU, Manac'h N, Rivoal J, Hill RD. Expression of a stress-induced hemoglobin affects $\mathrm{NO}$ levels produced by alfalfa root cultures under hypoxic stress. Plant J. 2003;35:763-70.

27. Dordas C, Hasinoff BB, Rivoal J, Hill RD. Class-1 haemoglobins, nitrate and $\mathrm{NO}$ levels in anoxic maize cell-suspension cultures. Planta. 2004;219:66-72.
28. Vigeolas H, Huhn D, Geigenberger P. Nonsymbiotic haemoglobin-2 leads to an elevated energy state and to a combined increase in polyunsaturated fatty acids and total oil content when overexpressed in developing seeds of transgenic Arabidopsis plants. Plant Physiol. 2011;155:1435-44.

29. Hebelstrup KH, Shah JK, Igamberdiev AU. The role of nitric oxide and haemoglobin in plant development and morphogenesis. Physiol Plant. 2013. https://doi.org/10.1111/ppl.12062.

30. Kuruthukulangarakoola GT, Zhang J, Albert A, Winkler B, Lang H, Buegger F, Gaupels F, Heller W, Michalke B, Sarioglu H, Schnitzler JP, Hebelstrup KH, Durner J, Lindermayr C. Nitric oxide-fixation by non-symbiotic haemoglobin proteins in Arabidopsis thaliana under N-limited conditions. Plant Cell Environ. 2017:40:36-50.

31. Vishwakarma A, Kumari A, Mur LAJ, Gupta K. A discrete role for alternative oxidase under hypoxia to increase nitric oxide and drive energy production. Free Radic Biol Med. 2018. https://doi.org/10.1016/j.freeradbio med.2018.03.045

32. Tiso M, Tejero J, Basu S, Azarov I, Wang X, Simplaceanu V, Frizzell S, Jayaraman T, Geary L, Shapiro C, Ho C, Shiva S, Kim-Shapiro DB, Gladwin MT. Human neuroglobin functions as a redox-regulated nitrite reductase. J Biol Chem. 2011;286:18277-89.

33. Tiso M, Tejero J, Kenney C, Frizzell S, Gladwin MT. Nitrite reductase activity of non-symbiotic hemoglobins from Arabidopsis thaliana. Biochemistry. 2012;51:5285-92

34. Kim-Shapiro DB, Schecter AN, Gladwin MT. Unrevealing the reactions of nitric oxide, nitrite, and hemoglobin in physiology and therapeutics. Arterioscler Thromb Vasc Biol. 2006;26:697-705.

35. Cassoly R, Gibson QH. Conformation, co-operativity and ligand binding in human hemoglobin. J Mol Biol. 1975;91:301-13.

36. Cooper CE. Nitric oxide and iron proteins. Biochim Biophys Acta. 1999;1411:290-309.

37. David A, Yadav S, Baluška F, Bhatla SC. Nitric oxide accumulation and protein tyrosine nitration as a rapid and long distance signalling response to salt stress in sunflower seedlings. Nitric Oxide. 2015;50:28-37.

38. Arora D, Jain P, Singh N, Kaur H, Bhatla SC. Mechanisms of nitric oxide crosstalk with reactive oxygen species scavenging enzymes during abiotic stress tolerance in plants. Free Radic Res. 2015:50:291-303.

39. Hill RD. What are hemoglobins doing in plants? Can J Bot. 1998:76:707-12.

40. Igamberdiev AU, Hill RD. Nitrate, NO and haemoglobin in plant adaptation to hypoxia: an alternative to classic fermentation pathways. J Exp Bot 2004;55:2473-82.

41. Igamberdiev AU, Baron K, Manac'h-little N, Stoimenova M, Hill RD. The haemoglobin/nitric oxide cycle: involvement in flooding stress and effects on hormone signalling. Ann Bot. 2005;96:557-64.

42. Gupta KJ, Hebelstrup KH, Mur LAJ, Igamberdiev AU. Plant hemoglobins: important players at the crossroads between oxygen and nitric oxide. FEBS Lett. 2011:585:3843-9.

43. Riquelme A, Hinrichsen P. Non-symbiotic hemoglobin and its relation with hypoxic stress. Chil J Agric Res. 2015. https://doi.org/10.4067/S0718 $-58392015000300009$

44. Perazzolli M, Dominici P, Romero-Puertas MC, Zago E, Zeier J, Sonoda M, Lamb C, Delledonne M. Arabidopsis nonsymbiotic hemoglobin AHb1 modulates nitric oxide bioactivity. Plant Cell. 2004;16:2785-94.

45. Doyle MP, Hoekstra JW. Oxidation of nitrogen-oxides by bound dioxygen in hemoproteins. J Inorg Biochem. 1981;14:351-8. 